Studies suggest that intraoperative ultrasonography can identify most patients with colorectal hepatic metastases at the time of surgery for the primary tumour.

Preliminary experience with intraoperative ultrasonography (A K Olsen, personal communication) suggests that resectable hepatic metastases will be found in about one in 10 patients undergoing apparently curative resection of primary large bowel cancer and that these can be excised by recently developed techniques for segmental resection. ${ }^{6} \mathrm{~A}$ further two in 10 patients will have unresectable hepatic disease because of too many deposits. Resection of conventionally detected hepatic metastases, which are apparently confined to the liver, produces long term survival in about one in four patients. ${ }^{6}$ Survival after resection of lesions detected by intraoperative ultrasonography may be better than after resection of the much larger tumours detected by conventional techniqueswhich have had longer to spread.

Patients in whom deposits detected by intraoperative ultrasonography are excised may also have hepatic metastases that are too small for detection by ultrasonography and may be missed by surgical resection. Thus detection of hepatic metastases by intraoperative ultrasonography may be more valuable in identifying patients in whom hepatic metastasis has occurred than in localising every deposit. Adjuvant intrahepatic infusion of fluorouracil has shown some survival advantage in large bowel cancer ${ }^{16}$ - presumably the benefit is in patients with occult hepatic metastases-and advanced colorectal hepatic metastases respond to intrahepatic infusion of fluorodeoxyuridine. ${ }^{17}$ Resection of hepatic metastases detected by intraoperative ultrasonography should therefore be followed by intrahepatic infusion of either fluorouracil or fluorodeoxyuridine to maximise the possibility of eradicating any microscopic foci of disease remaining within the liver in these "high risk" patients.
Randomised trials are needed in patients undergoing apparently curative resection of primary large bowel cancer to compare long term survival after conventional management with survival after intraoperative ultrasonography, resection of hepatic metastases, and intrahepatic infusion of either fluorouracil or fluorodeoxyuridine. As well as revealing any survival benefit, these trials will test our understanding of the biology of metastasis in large bowel cancer.

Senior Lecturer in Surgery,

T G ALLEN-MERSH

Westminster Hospital

London SWIP 2AP

1 Greenway B. Hepatic metastases from colorectal cancer: resection or not. Brf Surg 1988;75:513-9. 2 Weiss L, Grundman E, Torhorst J, Harveit F, Moberg I, Eber M, et al. Haematogenous metastatic patterns in colonic carcinoma: an analysis of 1541 necropsies. F Pathol 1986;150:195-203.

3 Finlay IG, Meek D, Brunton F, McArdle CS. Growth rate of hepatic metastases in colorectal carcinoma. Brf Surg 1988;75:641-4.

4 Smith TJ, Kemeny MM, Sugarbaker PH, Jones AE, Verness M, Shawker TH, et al. A prospective study of hepatic imaging in the detection of metastatic disease. Ann Surg 1982;195:486-91.

5 Matsui O, Takashima T, Kadoja M, Suzuki M, Hirose J, Kaweyama T, et al. Liver metastases from colorectal cancers: detection with CT during arterial portography. Radiology 1987;165:65-9.

6 Sugarbaker PH, Kemeny N. Management of metastatic cancer to the liver. Adv Surg 1989;22:1-56.

Steele G, Ravikumar TS. Resection of hepatic metastases from colorectal cancer. Ann Surg 1989;210:127-38.

8 Weiss L. Random and nonrandom processes in metastasis, and metastatic inefficiency. Invasion Metastasis 1983;3:193-207.

9 Palmer M, Petrelli NJ, Herrera L. No treatment option for liver metastases from colorectal adenocarcinoma. Dis Colon Rectum 1989;32:698-701.

10 Machi J, Isomoto H, Kurohiji J, Shirouzu K, Yamashita Y, Kakegawa T, et al. Detection of unrecognised liver metastases from colorectal cancers by routine use of operative ultrasonography. Dis Colon Rectum 1986;29:405-9.

11 Boldrini G, de Gaetano AM, Giovannini I, Castagneto M, Colagrande C, Castiglioni G. The systematic use of operative ultrasound for detection of liver metastases during colorectal surgery. World f Surg 1987;11:622-7.

12 Russo A, Sparacino G, Plaja S, Cajozza M, La Rosa C, Demma I, et al. Role of intraoperative ultrasound in the screening of liver metastases from colorectal carcinoma: initial experiences. f Surg Oncol 1989;42:149-55.

13 Olsen AK. Intraoperative ultrasound and the detection of liver metastases in patients with colorectal cancer. Br f Surg 1990;77:998-9.

14 Charnley RM, Morris DL, Dennison AR, Amar SS, Hardcastle JD. Detection of colorectal liver metastases using intraoperative ultrasound. $B r \mathcal{f}$ Surg 1991;78:45-8.

15 Ward BA, Miller DL, Frank JA, Dwyer AJ, Simmons JT, Chang R, et al. Detection of colorectal liver metastases: which imaging technique is best? Surgery 1989;105: 180-7.

16 Adjuvant $x$-ray and 5-FU infusional study (axis) protocol. Cambridge: MRC Cancer Trials Centre, 1990:6.

17 Allen-Mersh TG. Colorectal liver metastases: is no treatment still best? $\mathcal{F} R$ Soc Med 1989;82:2-3.

\title{
Fibrinogen
}

\section{An independent risk factor for cardiovascular disease}

Since the Northwick Park heart study showed that fibrinogen concentration was an independent risk factor for myocardial infarction ${ }^{12}$ five further epidemiological studies have produced prospective data on fibrinogen and cardiovascular events. ${ }^{3-7}$ All measured fibrinogen concentrations in large random samples of the population and related them to cardiovascular events several years later. From these studies fibrinogen concentration has emerged as an important and independent risk factor for stroke and myocardial infarction. In the most recent trial fibrinogen concentration, leucocyte count, and plasma viscosity were at least as predictive of coronary events as cholesterol concentration, diastolic blood pressure, and body mass index. ${ }^{7}$

That the fibrinogen concentration is raised after stroke ${ }^{8}$ and myocardial infarction' has been known for many years, although interpreting these findings is difficult given that fibrinogen is an acute phase protein and therefore likely to increase with inflammation or tissue necrosis. Recent work, however, suggests that fibrinogen concentration is raised before such events - for example, in patients with transient ischaemic attacks (p 605) ${ }^{1011}$ and with angina pectoris. ${ }^{12}$ More importantly perhaps, fibrinogen strongly predicts cardiovascular events in people with coronary heart disease ${ }^{9}$ and peripheral vascular disease ${ }^{13}$ and in survivors of a first stroke. ${ }^{14}$ It also predicts the progression of atherosclerotic carotid stenoses. ${ }^{15}$

This may be explained by fibrinogen concentration's positive correlation with nearly all other cardiovascular risk factors: age, hypertension, hyperlipoproteinaemia, smoking, diabetes, body mass index, stress, and lack of physical activity. ${ }^{16}$ Also relevant to an understanding of the links between fibrinogen concentration and cardiovascular disease are the findings that oral contraceptives increase the concentration of fibrinogen ${ }^{17}$ while moderate alcohol intake decreases it. ${ }^{18}$ Despite these associations fibrinogen concentration has emerged as an independent risk factor for cardiovascular disease. More than that, an increased fibrinogen concentration may be a common mechanism by which several major risk factors promote coronary artery disease. ${ }^{19}$

If this is so, how does fibrinogen damage the circulatory system? Several possibilities exist. It may promote a hypercoaguable state favouring the deposition of thrombus on atheromatous plaques, ${ }^{12}$ and it is an important determinant of blood rheology. ${ }^{16}$ Fibrinogen also links to platelet receptors, which is a precondition for platelet aggregation..$^{20}$ Multiple mechanisms exist whereby fibrinogen and its metabolites 
cause endothelial damage, disorganisation, and dysfunction. ${ }^{20}$

Should fibrinogen concentration be included in a person's cardiovascular risk profile and should attempts be made to lower it if it exceeds the limit suggested by epidemiological studies? ${ }^{1-7}$ Before doing this we need a reliable cut off point. Currently it differs widely among laboratories, mainly (although not exclusively) because of different techniques of measurement. Also needed is a compound that lowers fibrinogen concentration safely and selectively. Several drugs have been reported to lower fibrinogen concentrations, including ticlopidine, stanozolol, oxpentifylline, calcium dobesilate, propranolol, and nisoldipine, and the fibrates. But because they all have prominent pharmacological effects other than lowering fibrinogen concentration they are not ideally suited to elucidate further the relation between fibrinogen and cardiovascular events in intervention studies.

At present we can use the knowledge that a raised concentration of fibrinogen identifies people at risk of cardiovascular disease to strengthen our recommendations for adequate treatment for hypertension, lipid disorders, and diabetes and for relevant changes in lifestyle.

Professor of Medicine,

E ERNST

University Clinic for Physical Medicine and Rehabilitation,

Allgemeines Krankenhaus,

1090 Vienna

1 Meade TW, North WRS, Chakrabarti T, Stirling Y, Haines AP, Thompson SG. Haemostatic function and cardiovascular death: early results of a prospective study. Lancet 1980;i:1050-4.
2 Meade TW, Mellows S, Brozovic M, Miller GJ, Chakrabarti RA, North WR, et al. Haemostatic function and ischaemic heart disease: principal results of the Northwick Park heart study. Lancel 1986;ii:533-7.

3 Wilhelmsen L, Svärdsudd K, Korsan-Bengsten K, Larsson B, Tibblin G. Fibrinogen as a cardiovascular risk factor for stroke and myocardial infarction. N Engl f Med 1984;311:501-5.

Stone MC, Thorp JM. Plasma fibrinogen a major cardiovascular risk factor. $\mathcal{I} R$ Coll Gen Pract 1985;35:565-9.

5 Kannel WB, D'Agostino RB, Belanger AJ. Fibrinogen, and risk of cardiovascular disease. JAMA 1987;258:1183-6.

6 Balleisen L, Schulte H, Assmann G, Epping PH, Van De Loo J. Coagulation factors and the progress of coronary heart disease. Lancet 1987;i:462.

7 Yarnell JWG, Baker JA, Sweetnam PM, Bainton D, O'Brien JR, Whitehead PJ, et al. Fibrinogen, viscosity, and white blood cell count are major risk factors for ischemic heart disease. Circulation viscosity, and whice $1991 ; 83: 836-44$.

8 Eisenberg S. Blood viscosity and fibrinogen concentration following cerebral infarction. Circulation 1966;33/34(suppl 2): 10-4.

9 Dormandy J, Ernst E, Matrai A, Flute PT. Hemorheological changes following acute myocardial infarction. Am Hearl f 1982;104:1364-7.

10 Qizilbash N, Jones L, Warlow C, Mann J. Fibrinogen and lipid concentrations as risk factors for transient ischaemic attacks and minor ischaemic strokes. BMJ 1991;303:605-9.

11 Coull BM, Beamer N, De Garmo P, Sexton G, North F, Knox R, et al. Chronic blood hyperviscosity in subjects with acute stroke, transient ischemic attack, and risk factors for stroke. Stroke 1991;22:162-8.

12 Rainer Ch, Kawaniski DT, Chandraratna N, Bauersachs RM, Reid CL, Rahimtoola SH, et al. Changes in blood rheology in patients with stable angina pectoris as a result of coronary artery disease. Circulation 1987;76:15-20.

13 Dormandy JA, Hoare E, Colley J, Arrowsmith DE, Dormandy TL. Clinical, haemodynamic, rheological and biochemical findings in 126 patients with intermittent claudication. $B M \mathcal{J}$ 1973;iv:576-81.

14 Ernst E, Resch KL, Matrai A, Buhl M, Schlosser P, Paulsen HF. Impaired blood rheology as a risk factor for stroke. F Intern Med 1991;229:457-62.

15 Grotta JC, Yatsu FM, Pettigrew LC, Rhoades H, Bratina P, Vital D, et al. Prediction of carotid stenosis progression by lipid and hematologic measurements. Neurology 1989;39:1325-31.

16 Ernst E. Fibrinogen - an independent cardiovascular risk factor. I Intern Med 1990;227:365-72.

17 Ernst E, Schmölzl C, Matrai A, Schramm W. Hemorheological effects of oral contraceptives. Contraception 1989;40:571-80.

8 Meade TW, Chakrabarti R, Haines AP, North WRS, Stirling Y. Characteristics affecting fibrinolytic activity and plasma fibrinogen concentrations. $B M \mathcal{F} 1979 ; \mathrm{i}: 153-6$.

19 Lee AJ, Smith WCS, Lowe GDO, Tunstall Pedoe H. Plasma fibrinogen and coronary risk factors: the Scottish heart health study. F Clin Epidemiol 1990;43:913-9.

20 Cook NS, Ubben D. Fibrinogen as a major risk factor in cardiovascular disease. Trends Pharmacol Sci 1990;11:444-5

\section{Registers for occupational diseases}

\section{Helpful for surveillance, prevention, and research}

Doctors and patients have become much more aware of occupational diseases. Diagnostic methods have improved, and doctors more readily consider an occupational cause for illness. Accurate registers of occupational diseases help this process by providing the data necessary for surveillance, prevention, and research. But they are rare: few countries collect sufficiently accurate statistics, most relying on employers' records and claims made for workers' compensation.

To remedy this in the United Kingdom the British Thoracic Society and the Society of Occupational Medicine (supported by the Health and Safety Executive) set up a scheme of their own: the surveillance of work related and occupational respiratory diseases (SWORD). Its aims were to monitor the frequency of respiratory diseases related to work; to promote the early recognition, investigation, and control of new problems; to provide rapid feedback and information to participants; and to undertake collaborative investigations where indicated. The members of the two societies were asked to report to the project any newly diagnosed respiratory illness that they believed was due to occupational or work related exposure, and all participants received monthly feedback.

The first results have recently been published. ${ }^{1}$ Doctors reported 554 cases of occupational asthma to SWORD in 1989, of which 282 were attributed to agents on the prescribed list for which disablement benefits are payable (compared with the official figure of 222). The main difference was that SWORD's figures for cases of asthma due to isocyanates was nearly double the official figure. According to SWORD's returns, other named agents not on the prescribed list had induced 214 cases of asthma, and in 58 cases no agent was specified. More than twice as many cases of allergic alveolitis were reported to SWORD than there were people receiving disablement benefit for this condition. For some diseases, however-asbestosis, lung cancer, and byssinosis - the figures from the two sources of data were similar. The returns also provide annual incidences for various diagnostic groups and for occupational groups. The authors of this first report suspect that the true frequency of acute occupational respiratory diseases might be three times greater than has been reported.

In Finland the Institute of Occupational Health set up a register of occupational diseases nearly 30 years ago as a faster and more accurate alternative to the statistics of the Ministry of Social Affairs and Health. ${ }^{2}$ The register is based on the law that requires physicians to report every case of occupational disease or disease related to work. Since 1974 the register has obtained data from three different sources: reports of occupational disease filed by provincial medical officers, accident reports and diagnoses sent in by insurance companies (regardless of whether compensation was paid), and cases diagnosed at the Institute of Occupational Health. These data are published annually according to diagnosis, age, sex, industry, and occupation, with more detailed data available for research. An English edition is published. Comparing Finnish and British returns for 1989 shows that in Finland the reported incidence of allergic alveolitis was nearly 30 times and asthma six times higher than that in the United Kingdom.

Already the first year of SWORD has provided valuable new information, and as doctors' participation increases so 